\title{
ANALISIS KESEDIAAN MEMBAYAR WTP (WILLINGNESS TO PAY) DALAM UPAYA PENGELOLAAN OBYEK WISATA TAMAN ALUN KAPUAS PONTIANAK, KALIMANTAN BARAT
}

\author{
Fini Hasiani ${ }^{1}$, Endang Mulyani ${ }^{2}$, Erni Yuniarti ${ }^{1}$ \\ ${ }^{1}$ Program Studi Teknik Lingkungan, Fakultas Teknik, Universitas Tanjungpura, Pontianak \\ ${ }^{2}$ Program Studi Teknik Sipil, Fakultas Teknik, Universitas Tanjungpura, Pontianak \\ Emai : hasiani.fini@yahoo.com
}

\begin{abstract}
ABSTRAK
Berbagai fungsi yang terkait dengan sumber daya alam (fungsi ekologis, sosial, ekonomi, dan arsitektural) dan nilai estetika yang dimilikinya (obyek dan lingkungan) dapat meningkatkan kualitas lingkungan dan untuk kelangsungan kehidupan perkotaan juga dapat menjadi nilai kebanggaan dan identitas kota. Sebagai obyek wisata alam, Taman Alun-alun Kapuas belum tertata dengan baik, pelaksanaan upaya pengelolaan objek wisata Taman Alun Kapuas membutuhkan biaya yang tidak sedikit. Untuk itu diharapkan bagi pengunjung untuk membayar dalam pengelolaan Taman Alun Kapuas. Penelitian ini menggunakan analisis regresi logistik dalam menganalisis faktor-faktor kesediaan pengunjung untuk membayar. Sedangkan metode CVM (Contingen Valuation Method) digunakan untuk mengestimasi biaya yang akan dikeluarkan oleh pengunjung, dan metode regresi berganda digunakan untuk menganalisis faktor-faktor apa yang mempengaruhi besar kesediaan membayar pengunjung. Program yang dapat membantu dalam penelitian ini yaitu Microsoft Excel 2007 dan Minitab For Windows Realise 16. Hasil penelitian menunjukkan bahwa sebanyak $84 \%$ responden bersedia membayar dalam upaya pengelolaan lingkungan obyek wisata Taman Alun Kapuas. Faktor-faktor yang mempengaruhi kesediaan membayar responden pengunjung dalam upaya pengelolaan lingkungan obyek wisata Taman Alun Kapuas antara lain pendapatan (PNDPTN3) dan pengetahuan (PNGTHUAN). Nilai rata-rata WTP responden pengunjung adalah sebesar Rp 3360,00/orang. Faktor yang mempengaruhi nilai WTP responden yaitu usia (U).
\end{abstract}

Kata Kunci: WTP (Willingness to Pay), Taman Alun Kapuas, Minitab for Windows Reliase 16

\begin{abstract}
The functions associated with natural resource (function of ecological, social, economic, and architectural) and its aesthetic value (objects and environments) can improve the quality of the environment and to the sustainability of urban life can also be the value of the pride and identity of the city. As natural attractions, Alun Kapuas attraction Park is not well ordered, implementation of management measures Alun Kapuas park attraction requires no small cost. For visitors it is expected to pay for the management of Alun Kapuas park attractions. This study used logistic regression analysis to analyze the factors visitor willingness to pay. While CVM method (Contingent Valuation Method) is used to estimate the costs to be incurred by the visitors, and multiple regression analysis were used to analyze the factors that affect the willingness to pay of the visitors. Programs that can assist in this research that Microsoft Excel 2007 and Minitab For Windows Realise 16. The results showed that as many as $84 \%$ of respondents are willing to pay for the environmental management efforts Alun Kapuas attraction Park. Factors that influence the willingness to pay of respondents visitors in environmental management efforts Alun Kapuas Park attractions include income (PNDPTN3) and knowledge (PNGHTHUAN). The average value of WTP respondents was Rp 3360.00 / person. Factors affecting WTP values of respondents are age $(U)$.
\end{abstract}

Keywords: WTP (Willingness to Pay), Taman Alun Park, Minitab for Windows Reliase 16 


\section{Pendahuluan}

Sumber daya alam adalah semua yang terdapat di alam (kekayaan alam) yang dapat dimanfaatkan oleh manusia untuk mencukupi segala kebutuhan hidupnya. Sumber daya alam terbagi dua yaitu sumber daya alam hayati dan sumber daya alam non hayati. Sumber daya alam hayati disebut juga sumber daya alam biotik yaitu semua yang terdapat di alam (kekayaan alam) berupa makhluk hidup. Sedangkan sumber daya alam non hayati atau sumber daya alam abiotik adalah semua kekayaan alam yang dapat dimanfaatkan oleh manusia berupa benda mati (Rahmah, 2012).

Taman Alun Kapuas satu diantara tempat wisata yang ada di kota Pontianak. Taman Alun Kapuas terletak di Jalan Rahadi Usman atau di depan kantor Walikota Pontianak. Taman Alun Kapuas merupakan salah satu "open public space" yang cukup populer di kota Pontianak (Anak Kalbar, 2012).

Dilihat dari segi fungsinya Taman Alun Kapuas memiliki fungsi yang sama dengan fungsi RTH kota, yaitu sebagai nilai sosial dan budaya, ekologis, ekonomi, dan arsitektural. Fungsi-fungsi tersebut merupakan pendukung dan penambah nilai kualitas lingkungan dan budaya kota Pontianak, sehingga dapat berlokasi dan berbentuk sesuai dengan kebutuhan dan kepentingannya, seperti untuk keindahan, rekreasi, dan pendukung arsitektur kota (Dep.Pekerjaan Umum. 2012).

Untuk itu, diperlukan adanya kesediaan para pengunjung yang sengaja datang untuk membayar guna membantu pemerintah dalam mengola dan menata Taman Alun Kapuas dengan sebaik mungkin, hingga tidak hanya dapat menarik wisatawan domestik namun wisatawan internasional pun akan tertarik untuk datang ke Taman Alun kapuas.

Adapun tujuan penelitian ini yaitu : (1) Mengidentifikasi kondisi lingkungan sekitar Taman Alun Kapuas. (2) Mengidentifikasi karakteristik pengunjung terhadap kondisi lingkungan obyek wisata Taman Alun Kapuas. (3) Menganalisis faktor-faktor kesediaan pengunjung membayar dalam upaya pengelolaan obyek wisata taman Alun Kapuas. (4) Mengestimasi besarnya nilai WTP (Willingness to Pay) yang diberikan oleh pengunjung dalam upaya pelestarian lingkungan obyek wisata Taman Alun Kapuas. (5) Menganalisis faktor - faktor yang mempengaruhi nilai WTP pengunjung dalam upaya pengelolaan obyek wisata taman Alun Kapuas.

\section{Kajian Literatur}

Taman Alun Kapuas merupakan salah satu "open public space" yang cukup populer di kota Pontianak. Luas Taman Alun Kapuas saat ini sekitar tiga hektar. Dibangun sudah sejak zaman dulu, namun renovasi dilakukan pada tahun 1999. Saat ini pemerintah kota Pontianak terus melakukan pembenahan agar Taman Alun Kapuas dapat memberikan kenyaman bagi pengunjung. Satu diantaranya penyediaan tempat sampah, pos pengamanan dan pemasangan CCTV (Dinas Kebersihan, 2011).

\section{a. Taman Kota dan Ruang Terbuka Hijau}

Taman kota merupakan ruang terbuka diberbagai tempat suatu wilayah kota yang secara optimal digunakan sebagai areal penghijauan dan berfungsi baik secara langsung maupun tidak langsung untuk kehidupan dan kesejahteraan warga kotanya. Didalam penataan ruang perkotaan maka pembangunan taman kota harus menjadi komponen penting pola ruang kota (Sukawi, 2008).

Ruang terbuka hijau (RTH) dilihat dari terbentuknya, terdapat dua jenis RTH yaitu RTH

alami seperti habitat liar dan kawasan lindung, serta RTH buatan seperti pertanian kota, pertamanan kota, lapangan olah raga, pemakaman, dan lain-lain (Sukawi, 2008).

RTH sengaja dibangun secara merata di seluruh wilayah kota untuk memenuhi berbagai fungsi dasar yang secara umum dibedakan menjadi (Sukawi, 2008) :

a. Fungsi bio-ekologis (fisik), yang memberi jaminan pengadaan RTH menjadi bagian dari sistem sirkulasi udara (paru-paru kota), pengatur iklim mikro, agar sistem sirkulasi udara dan air secara alami dapat berlangsung lancer;

b. Fungsi sosial, ekonomi (produktif) dan budaya yang mampu menggambarkan ekspresi budaya local; 
c. Ekosistem perkotaan, produsen oksigen, tanaman berbunga, berbuah dan berdaun indah, serta bisa mejadi bagian dari usaha pertanian, kehutanan, dan lain-lain;

d. Fungsi estetis, meningkatkan kenyamanan, memperindah lingkungan kota baik (dari skala mikro: halaman rumah, lingkungan permukiman, maupun makro: lansekap kota secara keseluruhan).

Dari beberapa pengertian dan fungsi mengenai taman kota dan RTH, Taman Alun Kapuas merupakan taman kota (open space) dengan RTH buatan karena memiliki fungsi RTH pada umumnya yaitu fungsi sosial, ekonomi dan budaya, fungsi ekosistem perkotaan, dan fungsi estetis.

\section{b. Konsep Manajemen Pengelolaan dan Willingness to Pay}

Terdapat lima tahap kegiatan utama yang dilakukan dalam siklus hidup proyek yaitu (Hasan, 2002) :

- Inisiasi;

- Perencanaan dan desain;

- Pelaksanaan dan konstruksi;

- Pemantauan dan sistem pengendalian;

- Penyelesaian.

Willingness to Pay atau kesediaan untuk membayar adalah kesediaan individu untuk membayar terhadap suatu kondisi lingkungan atau penilaian terhadap sumberdaya alam dan jasa alami dalam rangka memperbaiki kualitas lingkungan (Hanley dan Spash, 1993).

Contingent Valuation Method (CVM) adalah salah satu metodologi berbasis survei untuk mengestimasi seberapa besar penilain seorang/masyarakat terhadap barang, jasa, dan kenyamanan. Metode ini banyak digunakan untuk mengestimasi nilai sesuatu yang tidak diperjual belikan di pasar, sementara metode preferensi-tersirat (revealed preference) tidak dapat digunakan.

\section{c. Metode Perhitungan Ekonomi}

Penilaian ekonomi atau economic valuation adalah sebuah upaya untuk memberikan nilai kuantitatif terhadap barang dan jasa yang dihasilkan sumberdaya alam dan lingkungan terlepas dari apakah nilai pasar tersedia bagi barang dan jasa tersebut. Terdapat 2 macam metode dalam perhitungan ekonomi yang tidak memiliki pasar (non-market), yaitu secara langsung (survei) dan tidak langsung (revealed WTP). Metode survey dilakukan dengan 2 macam cara yaitu Contingent Valuation Method (CVM) dan Discrete Choice Method, sedangkan metode tidak langsung dilakukan dengan 3 cara yaitu Travel Cost Method, Hedonic Pricing, dan teknik Random Utility Model. Metode yang sering digunakan dalam menghitung nilai Willingness to Pay (WTP) yaitu Contingent Valuation Method (CVM).

\section{d. Taman Alun Kapuas}

Taman Alun Kapuas merupakan salah satu "open public space" yang cukup populer di kota Pontianak. Alun Kapuas ini berada dipinggir tepian Sungai Kapuas, dengan memiliki air mancur dan replika Tugu Khatulistiwa. Taman alun kapuas dengan water front city nya merupakan tempat yang indah dan nyaman untuk bersantai sambil menikmati pemandangan sungai kapuas. Sebagaimana kota yang berada dekat dengan sungai yang merupakan pertemuan Sungai Kapuas dan Sungai Landak, kapal ferry atau sampan merupakan alat penyeberangan yang menjembatani pusat kota dengan pinggiran kawasan Siantan dan Kampung Beting (Dinas Kebudayaan dan Pariwisata, 2012).

Luas Taman Alun Kapuas saat ini sekitar tiga hektar. Dibangun sudah sejak zaman dulu, namun renovasi dilakukan pada tahun 1999. Saat ini pemerintah kota Pontianak terus melakukan pembenahan agar Taman Alun Kapuas dapat memberikan kenyaman bagi pengunjung. Satu diantaranya penyediaan tempat sampah, pos pengamanan dan pemasangan CCTV (Dinas Kebersihan, 2011). Selain itu, pada taman ini para pedagang yang bukan pedagang kuliner tidak diperkenankan berjualan. Tujuan dari pelarangan tersebut agar taman dapat tertata dengan rapi dan dapat 
memberikan kenyaman bagi pengunjung. Karena taman ini merupakan tempat wisata keluarga dan pedagang yang berjualan khusus pedagang kuliner saja (Anak Kalbar, 2012).

\section{Metodelogi Penelitian}

\section{a. Lokasi dan Waktu Penelitian}

Penelitian ini dilakukan di obyek wisata Taman Alun Kapuas Pontianak, Kalimantan Barat. Pemilihan lokasi ini dikarenakan dilihat dari beberapa obyek wisata yang ada di Pontianak, Taman Alun Kapuas merupakan obyek wisata yang memiliki sumber daya alam yang potensial sebagai obyek wisata. Pengambilan data ini dilakukan selama bulan Oktober 2012-Desember 2012. Penelitian dilakukan baik pada hari kerja (Senin-Jumat) maupun hari libur (Sabtu-Minggu). Tahap terakhir yaitu proses pengolahan dan analisis data serta penyusunan skripsi yang dilakukan pada bulan Januari 2012-April 2013.

\section{b. Jenis dan Sumber Data}

Jenis data yang digunakan dalam penelitian ini adalah data primer dan data sekunder. Data primer diperoleh dengan melakukan wawancara dengan responden dengan bantuan kuesioner. Data tersebut meliputi karakteristik pengunjung sekitar dan pengunjung taman wisata seperti, umur, jenis kelamin, status perkawinan, tingkat pendidikan, jenis pekerjaan, tingkat pendapatan, dll.

Data sekunder diperoleh dari instansi yang berhubungan dengan pengelolaan obyek wisata Taman Alun Kapuas, antara lain Dinas Kebudayaan dan Pariwisata, Badan Lingkungan Hidup, dan lain-lain. Data sekunder juga diperoleh dari literatur-literatur yang relevan dengan topik penelitian ini.

\section{c. Metode Pengambilan Sampel}

Metode yang akan digunakan yaitu metode sampling insidental yakni teknik penentuan sampel berdasarkan kebetulan yaitu siapa saja yang kebetulan/insidental bertemu. Sedangkan jumlah sampel pengunjung yang digunakan yaitu 100 sampel.

\section{d. Metode Analisis Data}

Data dan informasi yang diperoleh dalam penelitian ini akan dianalisis secara kualitatif dan kuantitatif. Pengolahan dan analisis data dilakukan dengan bentuan program Minitab for Windows Release 16. Sedangkan analisis peluang menggunakan analisis regresi logistic dan analisis faktor-faktor yang menentukan nilai WTP dilakukan dengan menggunakan analisis regresi berganda.

\section{Memperkirakan Nilai Rata-rata WTP}

Nilai rata-rata yang akan dikeluarkan oleh responden yang bersedia membayar dapat dihitung dengan menggunakan rumus dibawah ini :

$$
E W T P=\frac{\sum_{i=1}^{n} W i}{n}
$$

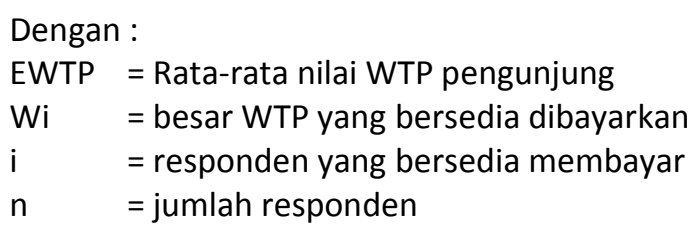




\section{Menjumlahkan Data}

Setelah menduga nilai tengah WTP maka selanjutnya diduga nilai total WTP dari responden dengan menggunakan rumus :

$$
T W T P=\sum_{i=1}^{n} W T P_{i}\left(\frac{n_{i}}{N}\right) P
$$

Dimana :

$$
\begin{array}{ll}
\sum_{\text {TWTP }} & =\text { Total WTP } \\
\text { WTPi } & =\text { WTP individu sampel ke- } i \\
n i & =\text { Jumlah sampel ke- } i \text { yang bersedia membayar sebesar WTP } \\
N & =\text { Jumlah sampel } \\
P & =\text { Jumlah populasi per } 3 \text { tahun terakhir } \\
i & =\text { Responden ke-i yang bersedia membayar }(i=1,2, \ldots, \mathrm{n})
\end{array}
$$

\section{Hasil dan Pembahasan}

\section{a. Karakteristik Responden}

Responden dalam penelitian ini adalah wisatawan dalam maupun luar kota Pontianak yang berkunjung ke obyek wisata Taman Alun Kapuas. Karakteristik responden sangatlah penting dalam penelitian ini karena dengan mengetahui karakteristik responden, maka akan mengetahui obyek penelitian dengan lebih baik. Jumlah keseluruhan responden yang menjadi obyek penelitian yaitu berjumlah 100 orang.

Dari grafik a dapat dilihat bahwa dari 100 responden yang diteliti, terdapat sebanyak $58 \%$ responden berjenis kelamin wanita, sedangkan sisanya yaitu sebesar $42 \%$ responden adalah pria. Berdasarkan pengamatan secara langsung, pengunjung yang menikmati Taman Alun Kapuas adalah pengunjung yang berjenis kelamin wanita, baik itu kaum remaja maupun dewasa. Kaum wanita cenderung lebih ingin bersantai dengan menikmati hal-hal yang indah, sejuk, dan dalam keramaian seperti membawa anak-anak mereka bermain dan bersantai.

Berdasarkan grafik $b$, maka dapat dilihat bahwa sebanyak 31\% pengunjung berusia $\leq 19$ tahun, sebanyak $11 \%$ berusia antara 30-39 tahun, sebanyak 7\% responden berusia 40-49 tahun, sebanyak $5 \%$ berusia $\geq 50$, dan sebanyak $46 \%$ responden berusia antara 20-29 tahun. Kelompok usia tersebut merupakan kelompok usia produktif yang banyak melakukan wisata. Menurut Soekadijo (1996), golongan umur yang produktiflah yang paling banyak mengadakan perjalanan wisata. Golongan produktif ini memerlukan rekreasi terutama untuk penyegaran dari kesibukannya seharihari. Garfik karakteristik responden dapat dilihat pada Gambar 1. (Data Kuesioner, 2013) :

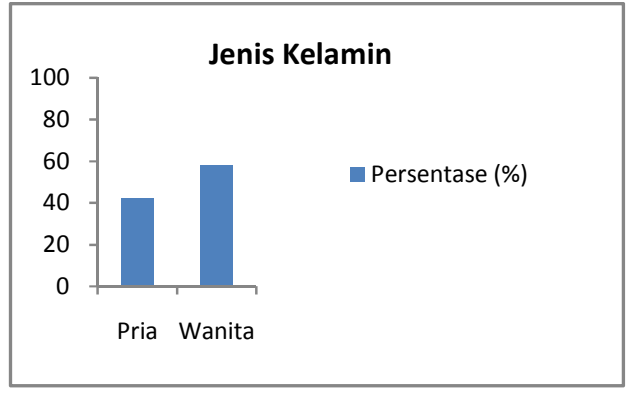

a. Berdasarkan Jenis Kelamin

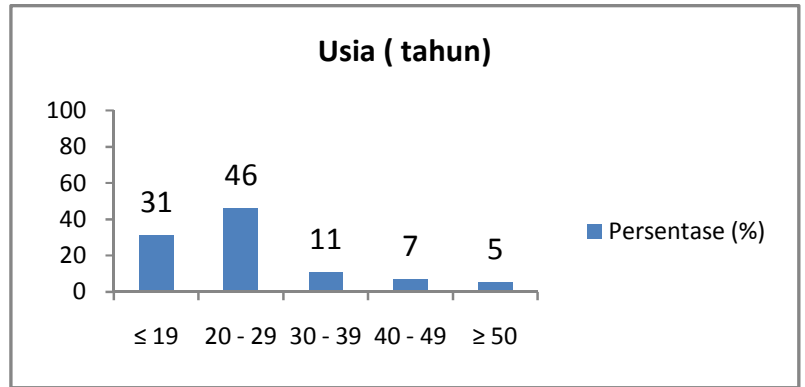

b. Berdasarkan Usia

Gambar 1. Grafik Karakteristik Responden Berdasarkan Jenis Kelamin Dan Usia

Status pernikahan juga menjadi faktor yang menyebabkan seseorang berkunjung untuk berekreasi. Seseorang yang belum menikah akan lebih sering berpergian dalam hal berekreasi karena mereka belum disibukkan oleh pekerjaan rumah tangga atau kewajiban dalam keluarga. Berikut ini adalah rekapitulasi data 100 responden berdasarkan status pernikahan : 
Tabel 1. Rekapitulasi Data Responden Berdasarkan Status Pernikahan

\begin{tabular}{|c|c|c|c|}
\hline No & Status & Jumlah (Orang) & Persentase (\%) \\
\hline 1 & Belum Menikah & 67 & 67 \\
\hline 2 & Menikah & 33 & 33 \\
\hline \multicolumn{2}{|c|}{ Jumlah } & $\mathbf{1 0 0}$ & $\mathbf{1 0 0}$ \\
\hline
\end{tabular}

Sumber : Olahan Data Kuesioner, 2013

Dari tabel tersebut, dapat dilihat bahwa sebanyak $67 \%$ responden dengan status belum menikah dan sebanyak 33\% responden dengan status menikah. Pengunjung yang datang ke lokasi juga cenderung datang bersama keluarganya, melainkan dengan teman-teman dan pasangannya.

Tingkat pendidikan yang lebih tinggi berpengaruh terhadap pemahaman dan rasa ingin tahu seseorang terhadap obyek wisata dibandingkan dengan seseorang yang tingkat pendidikannya lebih rendah. Selain itu tingkat pendidikan juga berpengaruh terhadap jenis pekerjaan seseorang, jenis pekerjaan akan mempengaruhi pendapatan, jumlah pendapatan akan menentukan pengeluaran biaya untuk berwisata. Berikut ini adalah rekapitulasi data 100 responden berdasarkan pendidikan terakhir :

Tabel 2. Rekapitulasi Data Responden Berdasarkan Pendidikan Terakhir

\begin{tabular}{|c|c|c|c|}
\hline No & Pendidikan Terakhir & Jumlah (Orang) & Persentase (\%) \\
\hline 1 & SD & 2 & 2 \\
\hline 2 & SLTP & 24 & 24 \\
\hline 3 & SLTA & 51 & 51 \\
\hline 4 & Diploma & 6 & 6 \\
\hline 5 & Sarjana & 17 & 17 \\
\hline \multicolumn{2}{|r|}{ Jumlah } & 100 & 100 \\
\hline
\end{tabular}

Sumber : Olahan Data Kuesioner, 2013

Pada tabel dapat dilihat bahwa pendidikan yang mayoritas terdapat pada responden yaitu pada tingkat SLTA atau sederajat yaitu sebanyak 51\%. Sebanyak $24 \%$ tingkat pendidikannya yaitu SLTP, 17\% pada tingkat Sarjana, 6\% diploma, dan responden dengan tingkat pendidikan SD yaitu sebanyak $2 \%$. Hal ini berhubungan dengan paradigma modern bahwa yang berpendidikan memiliki daya tarik alam sebagai media untuk menurunkan kadar kepenatan sehari-hari. Berikut ini adalah rekapitulasi data 100 responden berdasarkan tingkat pendapatan:

Tabel 3. Rekapitulasi Data Responden Berdasarkan Pendapatan

\begin{tabular}{|c|c|c|c|}
\hline No & Pendapatan (Rp) & Jumlah (Orang) & Persentase (\%) \\
\hline 1 & $\leq 1.000 .000$ & 64 & 64 \\
\hline 2 & $1.000 .000-1.900 .000$ & 17 & 17 \\
\hline 3 & $2.000 .000-2.900 .000$ & 10 & 10 \\
\hline 4 & $\geq 3.000 .000$ & 9 & 9 \\
\hline \multicolumn{2}{|r|}{ Jumlah } & 100 & 100 \\
\hline
\end{tabular}

Dari tabel diatas dapat dilihat bahwa sebanyak $64 \%$ responden berpendapatan $\leq \mathrm{Rp}$ 1.000.000, sebanyak $17 \%$ yaitu pada rentang antara $\mathrm{Rp} 1.000 .000-\mathrm{Rp} 1.900 .000$, dengan rentang pendapatan antara Rp 2.000 .000 - Rp 2.900 .000 sebanyak 10\%, dan sebanyak 9\% responden berpendapatan $\geq R p$ 3.000.000. hal ini menunjukkan bahwa pengunjung yang mengunjungi Taman Alun Kapuas terdiri dari semua kalangan masyarakat, baik tingkat bawah, menengah maupun tingkat atas. 


\section{b. Analisis Faktor-Faktor Kesediaan Membayar Pengunjung}

Berikut ini adalah variabel yang dianggap mempengaruhi kesediaan membayar pengunjung, dengan menggunakan analisis regresi logistic pada program Minitab, maka hasilnya yaitu:

Tabel 4. Hasil output Analisis Regresi Logit dengan Program Minitab

\begin{tabular}{|c|c|c|c|c|c|c|c|}
\hline Predictor & Coef & SE Coef & Z & $\mathrm{P}$ & Odds Ratio & Lower & Upper \\
\hline Constant & -5.25785 & 6.94150 & -0.76 & 0.449 & & & \\
\hline JK & 0.111175 & 0.932220 & 0.12 & 0.905 & 1.12 & 0.18 & 6.95 \\
\hline U & 0.202513 & 0.147267 & 1.38 & 0.169 & 1.22 & 0.92 & 1.63 \\
\hline STTS & 0.980826 & 1.48375 & 0.66 & 0.509 & 2.67 & 0.15 & 48.86 \\
\hline \multicolumn{8}{|l|}{ PNDDKN } \\
\hline 2 & 2.86121 & 5.22239 & 0.55 & 0.584 & 17.48 & 0.00 & 487435.52 \\
\hline 3 & 3.78238 & 5.09174 & 0.74 & 0.458 & 43.92 & 0.00 & 947901.61 \\
\hline 4 & -0.553201 & 5.17169 & -0.11 & 0.915 & 0.58 & 0.00 & 14517.83 \\
\hline 5 & 2.91241 & 5.35381 & 0.54 & 0.586 & 18.40 & 0.00 & 663766.89 \\
\hline \multicolumn{8}{|l|}{ PNDPTN } \\
\hline 2 & -0.723711 & 1.25426 & -0.58 & 0.564 & 0.48 & 0.04 & 5.67 \\
\hline 3 & -4.00163 & 1.90584 & -2.10 & 0.036 & 0.02 & 0.00 & 0.77 \\
\hline 4 & 17.6937 & 9753.14 & 0.00 & 0.999 & 48336518.00 & 0.00 & * \\
\hline $\begin{array}{l}\text { PNGTHUAN } \\
\text { JRK }\end{array}$ & \multicolumn{6}{|c|}{ JRK } & 1.01 \\
\hline 2 & 0.430913 & 1.01691 & 0.42 & 0.672 & 1.54 & 0.21 & 11.29 \\
\hline 3 & -1.75096 & 1.58237 & -1.11 & 0.268 & 0.17 & 0.01 & 3.86 \\
\hline 4 & 19.7642 & 12804.3 & 0.00 & 0.999 & $3.83250 \mathrm{E}+08$ & 0.00 & * \\
\hline \multicolumn{8}{|l|}{ BIAYA } \\
\hline 2 & 0.0873377 & 0.928756 & 0.09 & 0.925 & 1.09 & 0.18 & 6.74 \\
\hline 3 & 25.2198 & 6947.81 & 0.00 & 0.997 & $8.97027 E+10$ & 0.00 & * \\
\hline 4 & 4.82849 & 36535.8 & 0.00 & 1.000 & 125.02 & 0.00 & * \\
\hline
\end{tabular}

Output tersebut diawali dengan Response Information. Output ini menampilkan informasi yang berkaitan dengan kategori pada variabel respon, dimana untuk kasus ini variabel Li (peluang) pengunjung untuk membayar dengan dua kategori Ya sebanyak 84 orang dan kategori Tidak sebanyak 16 orang.

Pada output Logistic Regression Table, memuat informasi mengenai koefisien model pada masing - masing variabel, besarnya galat dari dugaan, nilai $Z_{\text {hitung, }} p$-value beserta odds ratio dengan selang kepercayaan terhadap odds ratio 95\%. Pada variabel JK (jenis Kelamin) didapatkan nilai $p$-value yaitu 0,905 , berarti nilai itu lebih besar dari $\alpha=5 \%$, hal ini menunjukkan bahwa hipotesis Ho diterima yang berarti varibel JK tidak berpengaruh terhadap kesediaan pengunjung untuk membayar. Sedangkan pada variabel PNDPTN3 dan PNGTHUAN nilai p-value adalah 0,036 dan 0,050 yang berarti nilai tersebut kurang dari $\alpha=5 \%$. Maka dapat disimpulkan bahwa Ho ditolak yang berarti kedua variabel tersebut secara parsial atau masing-masing mempengaruhi terhadap kesediaan pengunjung untuk membayar.

Odds ratio secara sederhana dapat dirumuskan: $\psi=e^{\beta}$, dimana e adalah bilangan 2,71828 dan $\beta$ adalah koefisien masing-masing variabel. Pada variabel jenis kelamin, nilai Odds ratio tidak begitu diperhatikan karena p-value nya tidak signifikan, oleh karena itu baik pria maupun wanita tidak begitu berpengaruh terhadap kesediaan membayar. 


\section{c. Analisis Faktor-Faktor Nilai WTP (Willingness to Pay) Pengunjung}

Berikut ini adalah hasil analisis faktor-faktor yang mempengaruhi nilai WTP pengunjung. Dengan bantuan program Minitab, maka variabel yang mempengaruhi adalah :

Tabel 5. Hasil output Analisis Regresi Logit dengan Program Minitab

\begin{tabular}{|l|c|c|l|l|l|l|}
\hline Predictor & Coef & SE & Coef & T & P & VIF \\
\hline Constant & 1911 & 1220 & 1.57 & 0.121 & & \\
JK & & 157.1 & 402.7 & 0.39 & 0.697 & 1.181 \\
U & & 68.92 & 30.04 & 2.29 & 0.024 & 2.841 \\
STTS & & -1.3 & 624.1 & -0.00 & 0.998 & 2.575 \\
PNDDKN & & -45.7 & 251.7 & -0.18 & 0.857 & 1.981 \\
PNDPTN & & 213.1 & 263.6 & 0.81 & 0.421 & 2.015 \\
JRK & & 48.9 & 235.4 & 0.21 & 0.836 & 1.143 \\
BIAYA & & -198.8 & 340.3 & -0.58 & 0.561 & 1.708 \\
PNGTHUAN & & -581.2 & 374.8 & -1.55 & 0.124 & 1.113 \\
\hline
\end{tabular}

Model dalam penelitian ini menghasilkan $\mathrm{R}^{2}$ sebesar $48,8 \%$ yang artinya $48,8 \%$ keragaman WTP pengunjung membayar diterangkan oleh keragaman variabel-variabel bebas penjelas yang terdapat pada model. Sedangkan sisanya sebesar $51,2 \%$ diterangkan oleh faktor-faktor lain yang tidak terdapat dalam model. Pada regresi logit sebelumnya dikatakan bahwa nilai $\mathrm{R}^{2}$ harus lebih besar dari $15 \%$, dari output yang dihasilkan maka penelitian ini dinilai cukup baik karena nilai $\mathrm{R}^{2}$ yang diperoleh lebih besar dari $15 \%$. Nilai $F_{\text {hitung }}$ sebesar 2,19 dengan nilai $P$ 0,035 menunjukkan bahwa variabel-variabel bebas secara bersama-sama berpengaruh nyata terhadap WTP pengunjung dalam membayar pada taraf $\alpha=5 \%$.

Dari output diatas dapat dilihat variabel yang berpengaruh nyata pada taraf $\alpha=5 \%$ adalah biaya Usia dengan arah positif. Hal ini berarti semakin tingginya tingkat pendidikan yang dikeluarkan responden tiap kali berkunjung, maka akan meningkatnya WTP pengunjung. Jika biaya kunjungan meningkat satu rupiah, maka besarnya WTPnya akan meningkat sebesar Rp 0.023,00.

Nilai VIF yang dihasilkan pada masing-masing variabel yaitu $<10$, hal ini menunjukkan bahwa tidak adanya multikolineritas suatu variabel terhadap variabel lainnya.

Variabel yang tidak berpengaruh nyata yaitu jenis kelamin (JK), status (STTS), pendidikan (PNDDKN), pendapatan (PNDPTN), pengetahuan (PNGTHUAN), jarak (JARAK) dan biaya (BIAYA). Variabel-variabel tersebut tidak berpengaruh karena nilai $p$-value nya melebihi batas kepercayaan yaitu $\alpha=5 \%$. Selain itu adanya kemungkinan responden tidak menjawab dengan benar karena situasi dan waktu.

\section{d. Pembahasan}

Pada output Logistic Regression Table, memuat informasi mengenai koefisien model pada masing - masing variabel, besarnya galat dari dugaan, nilai $Z_{\text {hitung, }} p$-value beserta odds ratio dengan selang kepercayaan terhadap odds ratio 95\%. Pada variabel JK (jenis Kelamin) didapatkan nilai $p$-value yaitu 0,905 , berarti nilai itu lebih besar dari $\alpha=5 \%$, hal ini menunjukkan bahwa hipotesis Ho diterima yang berarti varibel JK tidak berpengaruh terhadap kesediaan pengunjung untuk membayar. Sedangkan pada variabel PNDPTN3 dan PNGTHUAN nilai p-value adalah 0,036 dan 0,050 yang berarti nilai tersebut kurang dari $\alpha=5 \%$. Maka dapat disimpulkan bahwa Ho ditolak yang berarti kedua variabel tersebut secara parsial atau masing-masing mempengaruhi terhadap kesediaan pengunjung untuk membayar. Odds ratio secara sederhana dapat dirumuskan: $\psi=e^{\beta}$, dimana e adalah bilangan 2,71828 dan $\beta$ adalah koefisien masing-masing variabel. Pada variabel jenis kelamin, nilai Odds ratio tidak begitu diperhatikan karena $p$-value nya tidak signifikan, oleh karena itu baik pria maupun wanita tidak begitu berpengaruh terhadap kesediaan membayar. 
Dalam kasus variabel PNDPTN3 dengan odds ratio sebesar 0,02 dengan p-value 0,036, dapat diartikan bahwa pengunjung yang berpendidikan lebih tinggi peluang membayar adalah 0,02 kali dibandingkan pengunjung dengan umur yang lebih muda satu tahun, jika faktor yang lain pada mereka sama. Setelah mengetahui berapa besarnya rata-rata WTP yang dikeluarkan oleh 100 responden, dikaitkan dengan beberapa hipotesis yang dicantumkan pada bab terdahulu, maka nilai tersebut akan diambil berdasarkan hipotesis. Yaitu sebesar 35\% atau sebesar Rp 1000,00 akan diambil pada setiap kendaraan roda 4, kendaraan roda 2 dan WC umum. Jadi, untuk kendaraan roda 4 akan diambil retribusi WTP sebesar Rp 2000 (biaya normal) + Rp 1000 (WTP) = Rp 3000/kendaraan, sedangkan pada kendaraan roda 2 akan diambil retribusi WTP Rp 1000 (biaya normal) + Rp 1000 $(\mathrm{WTP})=\mathrm{Rp}$ 2000/kendaraan, dan dari WC umum Rp 1000 (biaya normal) + Rp 1000 (WTP) = Rp 2000/pengunjung yang menggunakan WC umum. Karena pemerintah kota tidak membayar gaji pada petugas parkir kendaraan dan petugas WC, maka dari retribusi parkir kendaraan dan WC umum, sebesar $50 \%$ akan dari pendapatan keseluruhan akan diberika kepada pemerintah kota dan $50 \%$ nya diambil oleh para petugas. Misalnya pada hari kerja (Senin-Jumat) jumlah kendaraan roda 2 sebanyak 200 kendaraan/hari, kendaraan roda 4 sebanyak 50 kendaraan/hari dan pengguna WC umum sebanyak 100 orang/hari. Maka total pendapatan untuk pemerintah kota perhari yaitu :

Kendaraan roda $2 \quad: 200 \times \operatorname{Rp} 2000=\operatorname{Rp~} 400.000-50 \%=R p 200.000 /$ hari

Kendaraan roda $4 \quad: 50 \times \operatorname{Rp} 3000=\operatorname{Rp~} 150.000-50 \%=\operatorname{Rp} 75.000 /$ hari

WC umum $\quad: 100 \times \operatorname{Rp~} 2000=$ Rp $200.000-50 \%=$ Rp 100.000/hari

Retribusi PKL $\quad: 96 \times$ Rp $800=$ Rp 76.800/hari

Maka total pemasukan dari WTP pengunjung untuk pemerintah kota adalah sebesar : Rp $200.000+$ Rp $75.000+\operatorname{Rp} 100.000+\operatorname{Rp} 76.800=$ Rp 451.800/hari.

Jumlah yang didapat tersebut akan meningkat pada hari libur. Penetapan $50 \%$ retribusi tersebut juga memerlukan sosialisasi dari pemerintah kota kepada masing-masing petugas agar tidak adanya timbul kecurangan dan kerugian pada masing-masing pihak.

\section{Kesimpulan}

Berdasarkan hasil penelitian ini maka dapat ditarik suatu kesimpulan bahwa :

1. Karakteristik pengunjung obyek wisata Taman Alun Kapuas pada saat penelitian yang diperoleh dari 100 orang responden menunjukkan bahwa mayoritas pengunjung berjenis kelamin wanita dengan status belum menikah. Usia antara 20-29 tahun. Pendidikan terakhir pengunjung yaitu SLTA dan mayoritas berprofesi sebagai mahasiswa. Tingkat pendapatan pengunjung yaitu $\leq$ Rp.1000.000/bulan. Responden menyatakan kondisi lingkungan dan kebersihan obyek wisata Taman Alun Kapuas baik. Responden menyatakan bahwa penyediaan fasilitas wisata dan fasilitas umum di obyek wisata Taman Alun Kapuas baik dan masih kurang memadai.

2. Hasil penelitian juga menunjukkan bahwa sebanyak $84 \%$ responden pengunjung bersedia membayar dalam upaya pengelolaan lingkungan obyek wisata Taman Alun Kapuas. Faktor-faktor yang mempengaruhi kesediaan membayar responden pengunjung dalam upaya pengelolaan lingkungan obyek wisata Taman Alun Kapuas antara lain pendapatan (PNDPTN3) dan pengetahuan (PNGTHUAN)

3. Nilai rata-rata WTP responden pengunjung adalah sebesar Rp 3360,00/orang. Faktor yang mempengaruhi nilai WTP responden yaitu usia (U). 


\section{Ucapan Terima Kasih}

Terima kasih yang sebesar-besarnya kepada Allah SWT dan Nabi Muhammad SAW. Untuk kedua orang tua saya, Bapak Sean Nazar, ST dan Ibu Suhati Ningsih yang telah memberikan dukungan berupa moriil dan materiil, kasih sayang dan kekuatan untuk saya hingga dapat menyelesaikan kuliah S1 saya.

Kepada dosen-dosen saya, Ibu Rizky Purnaini, ST., MT selaku Ketua Prodi Teknik Lingkungan, Bapak Winardi Yusuf, ST., MT selaku Dosen Pembimbing Akademik, Ibu Ir.Hj.RR.Endang Mulyani MT dan Ibu Erni Yuniarti, ST., M.Si selaku dosen Pembimbing Tugas Akhir saya, Bapak Anwar Azazi, SE., DEA dan Ibu Hj. Mira Sophia Lubis, MT selaku dosen penguji saya dan ibu-ibu dan bapakbapak dosen yang tidak dapat saya sebutkan satu persatu, terima kasih atas bimbingan dan ilmu yang kalian berikan, semoga semuanya dapat bermanfaat untuk kehidupan saya kedepan.

Semoga semua yang saya berikan dapat bermanfaat untuk orang banyak. Untuk itu sekali lagi saya mengucapkan Terima Kasih.

\section{Referensi}

Anak, Kalbar. Taman Alun -Alun Kapuas, Taman Terindah Sejagad Raya. April 2012. http://pecidasase.blogspot.com/2012/04/taman-alun-alun-kapuas-taman-terindah.html

Dinas Kebersihan Kota Pontianak. 2012. Peta Kota Pontianak. Kota Pontianak : Dinas Kebersihan.

Dinas Kebudayaan dan Pariwisata. 2012. Perkembangan Jumlah Pengunjung di Taman Alun Kapuas. Pontianak: Dinas Kebudayaan dan Pariwisata.

Dinas Pekerjaan Umum/RTH Wilayah Perkotaan/Lab. 2012. Perencanaan Lanskap Departemen Arsitektur Lanskap Fakultas Pertanian - IPB.

Hanley, N. and C.L. Spash. 1993. Cost Benefit Analysis and The Environment.

Hasan MI. 2002. Pokok-pokok Materi Metodologi Penelitian. Jakarta : Ghalia

Sukawi. 2008. Taman Kota dan Upaya Penurangan Suhu Lingkungan Perkotaan (Studi Kasus Kota Semarang). Gedung Prof Soedarto. SH Kampus UNDIP Tembalang Semarang. Indonesia. 